\title{
Occurrence of Antibiotics in Water and Sediment from Zizhuyuan Lake
}

\author{
Chunhui Zhang*, Jiawei Tang, Liangliang Wang, Xiangyu Gao, Xudan He \\ School of Chemical and Environmental Engineering, China University of Mining and Technology (Beijing), \\ Room 607, Yifu Science and Research Building, No. Ding 11, Xueyuan Road, Beijing, 100083, China
}

Received: 19 January 2015

Accepted: 18 February 2015

\begin{abstract}
The occurrence of 22 antibiotics, including eight quinolones, nine sulfonamides and five macrolides in water and sediment from Zizhuyuan Lake has been investigated in Beijing, China. Sediment samples were extracted by pressurized liquid extraction (PLE). Aqueous extracts from PLE and water samples were concentrated by solid-phase extraction (SPE) and detected by high-performance liquid chromatography-electrospray ionization tandem mass spectrometry (HPLC-ESI MS/MS). Antibiotics were detected in concentrations of up to $20 \mathrm{ng} / \mathrm{L}$ in water samples and $52.1 \mu \mathrm{g} / \mathrm{kg}$ in sediments. Quinolones were the most prevalent contaminants in water body, accounting for $63.4 \%$, while quinolones and macrolides were prominent in sediments, accounting for $55.1 \%$ and $41.7 \%$, respectively. The environmental risk assessment revealed that some antibiotics, in particular Ofloxacin (OFL) and Sulfamethoxazole (SMX), could cause high damage to algae and plants in the aquatic ecosystem.
\end{abstract}

Keywords: antibiotics, water body, sediment, lake, Persistent Organic Pollutants (POPs)

\section{Introduction}

Antibiotics, as an emerging class of environmental contaminants, have attracted increasing attention due to their adverse effects on non-target organisms and ecological environments $[1,2]$. Previous studies have estimated that the total amount of antibiotics consumed globally is about 100,000 to 200,000 tons per year, of which almost 25,000 tons are used in China alone [3]. Many antibiotics cannot be completely absorbed or metabolized in humans and animals, and a considerable fraction has eventually been transported to the environment, often in their original form without transformation [4]. Although some antibiotics degrade at a certain rate, most of them are replaced by ongoing wide use and induce the generation of various types of antibiotic-resistant bacteria, antibiotics constitute a long-term potential threat to the health of humans and the ecological environment $[5,6]$.

*e-mail: truemanjung@163.com
So far, antibiotics have been detected in many environmental compartments, including sewage effluent, river water, seawater, sediments, and even groundwater in many regions and countries [7-11]. It has been demonstrated that many rivers and coastal waters have been seriously polluted and the concentration of certain antibiotics can even reach $\mathrm{mg} / \mathrm{L}$ level [12]. Antibiotics in water may potentially bioaccoumulate in aquatic animals and plants. Consequently, it is important to detect antibiotics in water environments. However, much less information is available for the occurrence and distribution of antibiotics in urban lakes.

Upstream of Zizhuyuan Lake, originating from Miyun Reservoir, is the most significant source of drinking water for Beijing, the capital of China with a population of 21 million, and the discharged antibiotics that remain in the water have been posed as a potential threat to aquatic organisms and eventually citizens. However, antibiotic residues in this area have not been investigated. So the aim of this study was to focus on the occurrence and distribu- 
tion of antibiotics in both water body and sediments, and to investigate the potential hazards of selected antibiotics on aquatic organisms, which will provide important data for decision-making.

\section{Materials and Methods}

\section{Chemicals}

HPLC-grade methanol and acetonitrile were purchased from Fisher Scientific (Pittsburgh, PA, USA). Formic acid (98\%) was purchased from Fluka. Ammonium formate (99\%) and ammonium hydroxide (v/v, 50\%) were purchased from Alfa Aesar. De-ionized (DI) water (>18.2 MX $\mathrm{cm}^{-1}$ ) was prepared with the Milli-Q Advantage A10 system (Millipore, USA).

Norfloxacin (NOR, 99.9\%), ciprofloxacin (CIP, 99.9\%), sarafloxacin (SAR, 95.0\%), ofloxacin (OFL, 99.9\%), fleroxacin (FLE, 99.5\%), lomefloxacin (LOM, 98.0\%), difloxacin (DIF, 98.0\%), enrofloxacin (ENR, 99.9\%), sulfadiazine (SDZ, 99.7\%), sulfamerazine (SMR, 99.9\%), sulfadimethoxine (SDM, 99.4\%), sulfisoxazole (SIA, 99.0\%), sulfamonomethoxine (SMM, 99.0\%), erythromycin (ERY, $99.1 \%$ ), roxithromycin (ROX, 90.0\%), josamycin (JOS, 98.0\%), tylosin (TYL, 82.4\%), and spiramycin (SPI, 88.9\%) were purchased from Sigma-Aldrich (St. Louis, MO, USA). Sulfamethoxazole (SMX, 99.0\%), sulfathiazole (STZ, 99.0\%), sulfapyridine (SPD, 99.0\%), and sulfamethazine (SMZ, 99.0\%) were purchased from KaSei Industry Co., Ltd. (Tokyo, Japan).

The following isotopically labelled compounds were used as surrogate standards at $100.0 \mu \mathrm{g} / \mathrm{L}$ in methanol. Norfloxacin- $\mathrm{d}_{5}\left(\mathrm{NOR}-\mathrm{d}_{5}\right)$, ofloxacin- $\mathrm{d}_{3}\left(\mathrm{OFL}-\mathrm{d}_{3}\right)$ and sarafloxacin- $\mathrm{d}_{8}\left(\mathrm{SAR}-\mathrm{d}_{8}\right)$ were purchased from SigmaAldrich (St. Louis, MO, USA). Sulfamethoxazole-d $\mathrm{d}_{4}$ $\left(S M X-d_{4}\right)$, sulfamethazine- $d_{4}\left(S M Z-d_{4}\right)$, spiramycin $\mathrm{I}_{-} \mathrm{d}_{3}$ (SPI I- $\left.\mathrm{d}_{3}\right)$, and erythromycin $-{ }^{13} \mathrm{C}, \mathrm{d}_{4}\left(E R Y-{ }^{13} \mathrm{C}, \mathrm{d}_{4}\right)$ were purchased from Toronto Research Chemicals (Oakville, ON, Canada).

\section{Sampling Sites and Sample Collection}

Zizhuyuan Lake, located at the western $3^{\text {rd }}$ ting-road of Beijing and accepted downstream of Miyun Reservoir, covers an area of about $160,000 \mathrm{~m}^{2}$. Water body and sediment sampling was collected from March to July 2014 from Zizhuyuan Lake, from six selected locations (Fig. 1). Site A was located at the entrance of the lake; Site B was at the center of the lake; Site C was at the southern end of the lake, a fishery on the left side. Sites D and E were on the western and eastern parts of the lake, Site F was downtown of the lake, which received both Jingmi Channel and Shuangzi Channel. Each site sampling was collected four times through two months and the average value of each point was calculated for four samples of each antibiotic. From these data, we concluded the maximum, minimum, and mean of each antibiotic in the lake.
Four liters of water samples at a depth of $1.0 \mathrm{~m}$ were collected using a transparent organic glass water sampler and placed in pre-rinsed brown glass bottles. Sediments $(0 \mathrm{~cm}$ to $5 \mathrm{~cm})$ were collected using a grab sampler from the bottom of the lake. All sampling equipment was thoroughly cleaned with acetone, then deionized water and Milli-Q pure water prior to field work. The water and sediment samples were transported to the laboratory in an icebox. Sediments were stored at $-20^{\circ} \mathrm{C}$. Water samples were treated within $12 \mathrm{~h}$ after collection. The analysis of sediments was completed within $7 \mathrm{~d}$.

\section{Sample Preparation and Analysis}

Chemical analysis was performed following EPA method 1694 developed by the U.S. Environmental Protection Agency with some modifications (EPA, 2007). Target antibiotics were extracted from water samples using AutoTrace SPE 280 (Dionex, USA) with an Oasis HLB cartridge ( $6 \mathrm{~mL}, 200 \mathrm{mg}$; Waters, USA), and from sediment samples with an ASE 350 pressurized liquid extraction (PLE) system (Dionex, Sunnyvale, CA, USA) and then purified using an HLB cartridge.

Water samples were filtered through nylon film $(0.45$ $\mu \mathrm{m})$. Before extraction with an Oasis HLB cartridge, a total of $0.2 \mathrm{~g} \mathrm{Na}_{2}$ EDTA and $20 \mathrm{ng}$ surrogate standards (NOR-d $\mathrm{d}_{5}$, OFL- $\mathrm{d}_{3}$, SAR- $\mathrm{d}_{8}$, SDMD- $\mathrm{d}_{4}, \mathrm{SMX}-\mathrm{d}_{4}$, ERY- ${ }^{13} \mathrm{C}, \mathrm{d}_{4}$, and SPI $\mathrm{I}-\mathrm{d}_{3}$ ) were added to the $200 \mathrm{ml}$ water sample. The HLB cartridges were preconditioned with $5 \mathrm{ml}$ methanol and $5 \mathrm{ml}$ DI water. Samples were then loaded and passed through the cartridges at a flow rate of around $3 \mathrm{ml} \cdot \mathrm{min}^{-1}$. After that, cartridges were rinsed with $15 \mathrm{ml}$ DI water, and then dried under nitrogen gas for $20 \mathrm{~min}$. Finally, the analytes were eluted with $6 \mathrm{ml}$ of ammonia-methanol solution (5:95, $\mathrm{V} / \mathrm{V})$. The eluate was concentrated to $1 \mathrm{ml}$ with nitrogen gas at $35^{\circ} \mathrm{C} .15 \mu \mathrm{L}$ of this solution was prepared for analysis.

A total of $0.1 \mathrm{~g}$ of pretreated lyophilized sediment sample was spiked with $20 \mathrm{ng}$ of internal standard (norfloxacin$\mathrm{d}_{5}$, ofloxacin- $\mathrm{d}_{3}$, sarafloxacin- $\mathrm{d}_{8}$, sulfamethoxazole- $\mathrm{d}_{4}$, sulfamethazine- $\mathrm{d}_{4}$, spiramycin $\mathrm{I}-\mathrm{d}_{3}$, and erythromycin $-{ }^{13} \mathrm{C}_{3}$ )

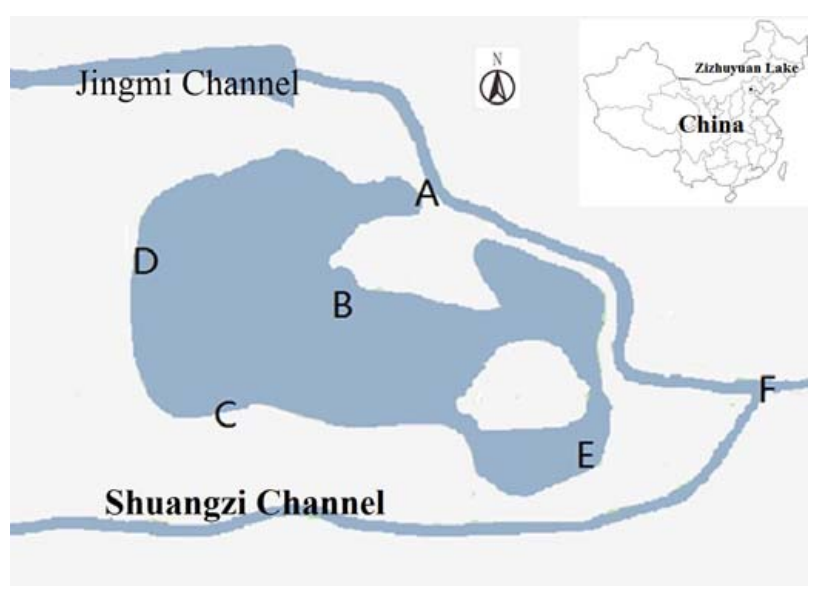

Fig. 1. The sampling sites of Zizhuyuan Lake. 
before being thoroughly mixed with $3 \mathrm{~g}$ of EDTA-washed diatomite from Varian (Walnut Creek, KS, USA). The mixture was put into a $10 \mathrm{~mL}$ stainless steel extraction cell with $100 \%$ methanol as the extracting solvent. The extraction conditions were as follows: extraction temperature, $70^{\circ} \mathrm{C}$; extraction pressure, $10.34 \mathrm{MPa}$; preheating period, $5 \mathrm{~min}$; static extraction, $10 \mathrm{~min}$; final extraction volume, $60 \mathrm{~mL}$; flush volume $60 \%$ of cell volume; nitrogen purge, $100 \mathrm{~s}$; and number of extraction cycles, 2 .

After extraction, a total of $25 \mathrm{~mL}$ extract was transferred to $100 \mathrm{~mL}$ round-bottom flask and then concentrated with an RE-2000 rotary evaporator (Yarong, Shanghai, China) to a final volume of about $1 \mathrm{~mL}$ at $37^{\circ} \mathrm{C}$ and $0.08 \mathrm{MPa}$. After concentration, the extract was immediately transferred to a $100 \mathrm{~mL}$ conical tube and then diluted to a final volume of $100 \mathrm{~mL}$ with DI water.

The SPE procedure was the same as that used for treating water samples. The eluate was concentrated to $1 \mathrm{~mL}$ under a gentle stream of nitrogen at $35^{\circ} \mathrm{C}$ before being dissolved with $1 \mathrm{~mL}$ of a mixture of methanol/aqueous solution of $0.05 \%$ formic acid $(10: 90 \mathrm{v} / \mathrm{v})$. Then the extract was centrifuged for $5 \mathrm{~min}$ at $12,000 \mathrm{rpm}$. Finally, the supernatant was filtered through a $0.22 \mu \mathrm{m}$ nylon filter, and $15 \mu \mathrm{L}$ of this solution was prepared for analysis.

High-performance liquid chromatography-electrospray ionization tandem mass spectrometry (HPLC-ESI MS/MS) was applied to analyze the target antibiotics. The LC system was Dionex Liquid Chromatography Ultimate 3000 (Sunnyvale, CA, USA). An XTerra MS C18 column ( $3 \mu \mathrm{m}$, $100 \mathrm{~mm} \times 2 \mathrm{~mm}$ ) was used as the analytical column at a flow rate of $0.20 \mathrm{~mL} \cdot \mathrm{min}^{-1}$. Methanol-acetonitrile $(1: 1, \mathrm{v} / \mathrm{v})$ was used as mobile phase $\mathrm{A}$, and $0.3 \%$ formic acid in water (containing $0.1 \%$ ammonium formate, $\mathrm{v} / \mathrm{v}, \mathrm{pH}=2.9$ ) was used as mobile phase B. The gradient program was as follows: the mobile phase starting conditions were $10 \%$ of $\mathrm{A}$ for $2.0 \mathrm{~min}$, and $\mathrm{A}$ was increased to $70 \%$ in $10.0 \mathrm{~min}$ before being increased to $100 \%$ in $4.0 \mathrm{~min} ; 100 \%$ of A for $3.0 \mathrm{~min}$, followed by returning to the initial composition in $0.1 \mathrm{~min}$, which was maintained for $13.9 \mathrm{~min}$. The total run time was $33.0 \mathrm{~min}$. The quantitative analyses were conducted using ESI/MS/MS (API 3200; Applied Biosystems/MDS SCIEX US).

\section{Quality Assurance and Quality Control}

The calibration curves for analyte detection were obtained by performing a linear regression analysis on spiked samples. The antibiotic concentrations in the samples were quantified using the internal standard method. The linearity obtained for all analytes was good in the investigated ranges for the sediment and water matrices, with correlation coefficients greater than 0.98 .

Recoveries of antibiotics in the water and sediment samples were tested. The recoveries of antibiotics ranged from $72.4 \%$ to $121.0 \%$ in water and from $63.4 \%$ to $132.2 \%$ in sediment, respectively. The limit of detection (LOD) calculated with a signal/noise ratio of 3 was $0.01 \mathrm{ng} / \mathrm{L}$ to 0.15 $\mathrm{ng} / \mathrm{L}$ for water and $0.1 \mu \mathrm{g} / \mathrm{kg}$ to $0.5 \mu \mathrm{g} / \mathrm{kg}$ for sediment.

\section{Risk Characterization}

Risk assessment for the aquatic compartment has been performed according to the guidelines for the risk assessment of new and existing medicinal products in the environment (EMEA, 2012a), as well as its associated Technical Guidance Document elaborated upon by the EMEA (EMEA, 2012b). According to these documents, risk evaluation is performed calculating the hazard quotient (HQ):

$$
\mathrm{HQ}=\mathrm{MEC} / \mathrm{PNEC}
$$

...where MEC is the maximum measured environmental concentration and PNEC is the predicted no-effect concentration in water. In practice, PNEC is calculated by dividing the lowest short-term $\mathrm{L}(\mathrm{E}) \mathrm{C}_{50}$ by an assessment factor (AF). As presented in:

$$
\mathrm{PNEC}=\mathrm{L}(\mathrm{E}) \mathrm{C}_{50} / \mathrm{AF}
$$

$\mathrm{LC}_{50}$ or $\mathrm{EC}_{50}$ is the lowest median effective concentration value obtained from the available literature, and AF is an appropriate standard assessment factor. In this study, the value of $\mathrm{AF}$ was chosen to be 100 to show chronic toxicity $[13,14]$.

\section{Results and Discussion}

\section{Antibiotics in Water Body}

Table 1 outlines a summary of the maximum, minimum, and means concentrations found, together with the frequency of each compound in the four matrices analyzed. A total of 14 out of 22 target antibiotics were detected in the water samples. The concentrations of detected quinolones, sulfonamides, and macrolides in the water were in the range of 9.02-26.62 ng/L, 2.05-13.46 ng/L, and 3.18-6.94 ng/L, with the mean concentration of $3.27 \mathrm{ng} / \mathrm{L}, 0.85 \mathrm{ng} / \mathrm{L}$ and $1.45 \mathrm{ng} / \mathrm{L}$, respectively.

The highest concentration was determined for Ofloxacin (OFL) at $20 \mathrm{ng} / \mathrm{L}$ at site D in water samples. This was mainly because of the nearby hospital, and OFL was a kind of widely used medicine in humans. OFL was the principal pollutant with the highest mean concentration of 7.00 $\mathrm{ng} / \mathrm{L}$, followed by NOR with a mean concentration of 6.27 , and the two quinolones accounted for $81.0 \%$ of QNs in water. Although the other 12 antibiotics were also found in water samples, only three of them were detected at relatively high concentrations. The average concentrations of SAR, SMX, and ROX in water were 2.04, 4.39, and 3.70 $\mathrm{ng} / \mathrm{L}$, respectively. However, the mean concentrations of other antibiotics were below $1.0 \mathrm{ng} / \mathrm{L}$.

Composition distribution of antibiotics in water showed that QNs were the predominant antibiotics (63.4\%) in all samples (Fig. 2). They were more frequently detected in water because of their heavy use in both human and veterinary medicines and had relatively higher concentrations and detection frequencies than SAs and MCs. From Fig. 3 it can be concluded that human activities played an impor- 
Table 1. Concentrations of antibiotics in water and sediment from Zizhuyuan Lake.

\begin{tabular}{|c|c|c|c|c|c|c|c|c|c|c|c|c|}
\hline \multirow{2}{*}{ Analytes } & \multicolumn{6}{|c|}{ Water $(\mathrm{n}=7, \mathrm{ng} / \mathrm{L})$} & \multicolumn{6}{|c|}{ Sediment $(n=7, \mu g / k g)$} \\
\hline & $\operatorname{Max}^{a}$ & $\sigma_{(\mathrm{n}=4)}^{\mathrm{a}}$ & $\operatorname{Min}^{\mathrm{b}}$ & $\sigma_{(\mathrm{n}=4)}^{\mathrm{b}}$ & Mean & $\mathrm{Fre}^{\mathrm{c}}$ & $\operatorname{Max}^{\mathrm{a}}$ & $\sigma_{(n=4)}^{a}$ & $\operatorname{Min}^{\mathrm{b}}$ & $\sigma_{(\mathrm{n}=4)}^{\mathrm{b}}$ & Mean & $\mathrm{Fre}^{\mathrm{c}}$ \\
\hline NOR & 7.1 & 0.985 & 4.62 & 1.167 & 6.27 & 100 & 34.2 & 4.089 & 2.75 & 0.276 & 8.69 & 100 \\
\hline CIP & 2.08 & 0.595 & ndd & & 0.9 & 50 & nd & & nd & & nd & 0 \\
\hline DIF & 0.39 & 0.167 & nd & & 0.174 & 66.7 & nd & & nd & & nd & 0 \\
\hline ENR & nd & & nd & & nd & 0 & nd & & nd & & nd & 0 \\
\hline FLE & nd & & nd & & nd & 0 & nd & & nd & & nd & 0 \\
\hline OFL & 20 & 3.874 & 1.8 & 0.528 & 7 & 100 & 7.6 & 0.815 & 1.45 & 0.299 & 3.04 & 100 \\
\hline LOM & nd & & nd & & nd & 0 & nd & & nd & & nd & 0 \\
\hline SAR & 8.92 & 1.569 & nd & & 2.04 & 33.3 & nd & & nd & & nd & 0 \\
\hline STZ & nd & & nd & & nd & 0 & nd & & nd & & nd & 0 \\
\hline SMX & 12.48 & 2.759 & 1.6 & 0.662 & 4.39 & 100 & nd & & nd & & nd & 0 \\
\hline SIA & 0.14 & 0.051 & nd & & 0.02 & 16.7 & 0.4 & 0.117 & 0.31 & 0.052 & 0.36 & 100 \\
\hline SPD & 0.32 & 0.1 & nd & & 0.13 & 83.3 & 0.18 & 0.052 & nd & & 0.04 & 33.3 \\
\hline SDM & nd & & nd & & nd & 0 & 0.34 & 0.048 & nd & & 0.09 & 33.3 \\
\hline SMZ & 0.116 & 0.026 & 0.036 & 0.007 & 0.1 & 100 & 0.35 & 0.045 & 0.12 & 0.037 & 0.17 & 100 \\
\hline SDZ & 0.38 & 0.073 & 0.05 & 0.013 & 0.157 & 100 & 0.2 & 0.019 & nd & & 0.03 & 16.7 \\
\hline SMR & nd & & nd & & nd & 0 & nd & & nd & & nd & 0 \\
\hline SMM & 1.25 & 0.138 & nd & & 0.31 & 66.7 & nd & & nd & & nd & 0 \\
\hline SPI & 0.372 & 0.059 & nd & & 0.16 & 83.3 & nd & & nd & & nd & 0 \\
\hline JOS & nd & & nd & & nd & 0 & nd & & nd & & nd & 0 \\
\hline TYL & nd & & nd & & nd & 0 & nd & & nd & & nd & 0 \\
\hline ERY & 1.44 & 0.094 & 0.13 & 0.028 & 0.49 & 100 & nd & & nd & & nd & 0 \\
\hline ROX & 5.5 & 0.37 & 2.72 & 0.347 & 3.7 & 100 & 52.1 & 3.765 & 0.2 & 0.041 & 8.887 & 100 \\
\hline
\end{tabular}

a: Maximum; ${ }^{\text {b: }}$ Minimum; ${ }^{\text {c: }}$ Frequency $(\%)$; ${ }^{\text {d: }}$ Not detected; $\sigma$ : standard deviation $(n=4)$

tant role in the distribution of antibiotics in Zizhuyuan Lake. Low levels of antibiotics were determined both at the entrance and the exit of the lake. Relatively high levels of antibiotics were detected at densely populated scenic spots and the fish farm (Sites B, C, and D).

Compared with the former studies, the concentrations detected in our study were much lower than those reported in Baiyangdian Lake in China (NOR, mean: $28.6 \mathrm{ng} / \mathrm{L}$; OFL, mean: $9.23 \mathrm{ng} / \mathrm{L}$; SMX, mean: $240 \mathrm{ng} / \mathrm{L}$; ROX, mean: $27.2 \mathrm{ng} / \mathrm{L}$; ERY, mean: $19.5 \mathrm{ng} / \mathrm{L}$;) [15] and in Spain (NOR, maximum: $54 \mathrm{ng} / \mathrm{L}$; OFL, maximum: $400 \mathrm{ng} / \mathrm{L}$; SMX, maximum: $33 \mathrm{ng} / \mathrm{L}$; SAR, maximum: $55 \mathrm{ng} / \mathrm{L}$; ROX, maximum: $12 \mathrm{ng} / \mathrm{L})$ [16].

\section{Antibiotics in Sediments}

In the sedimentary phase, only five target antibiotics showed high detection rates (NOR, OFL, SIA, SMZ, and ROX), while the others were either detected below the
LOD or were not detected frequently with low concentrations. The highest concentration was determined for Roxithromycin (ROX) at $52.1 \mu \mathrm{g} / \mathrm{kg}$ at Site C, with the highest mean concentration of $8.67 \mu \mathrm{g} / \mathrm{kg}$, followed by NOR and OFL with average concentrations of $8.69 \mu \mathrm{g} / \mathrm{kg}$ and $3.04 \mu \mathrm{g} / \mathrm{kg}$, respectively. The three compounds accounted for over $96.7 \%$ of all antibiotics in sediments. The mean concentrations of other detected antibiotics were all below $0.5 \mu \mathrm{g} / \mathrm{kg}$.

From Fig. 2, it can be concluded that QNs and MCs were the predominant antibiotics in sediments, accounting for $55.1 \%$ and $41.6 \%$ of the total antibiotics, respectively. Significant differences in the distribution of antibiotics existed between water and sediments in the lake. As shown in Table 1, CIP, DIF, SAR, SMX, SMM, SPI, and ERY were only detected in the water, while SIA was only detected in the sediments. As previously reported, SAs always exhibited the lowest mean concentration and detection frequency in sediments [17] and the high concentrations of 
Table 2. Hazard quotients (HQs) for aquatic organisms.

\begin{tabular}{|c|c|c|c|c|c|c|}
\hline Groups & Analytes & Taxonomic group & $\mathrm{L}(\mathrm{E}) \mathrm{C}_{50}(\mathrm{mg} / \mathrm{L})$ & PNEC (ng/L) & MEC (ng/L) & HQ \\
\hline \multirow{6}{*}{ QNs } & \multirow{3}{*}{ NOR } & Algae & 50.18 (96 h) & 5018 & 7.1 & 0.0014 \\
\hline & & Plant & $0.913(7 \mathrm{~d})$ & 91.3 & & 0.078 \\
\hline & & Invertebrate & 194.98 (48 h) & 19498 & & 0.0003 \\
\hline & \multirow{3}{*}{ OFL } & Algae & $0.021(24 \mathrm{~h})$ & 2.1 & 20 & 9.52 \\
\hline & & Plant & $0.126(24 \mathrm{~h})$ & 12.6 & & 1.58 \\
\hline & & Invertebrate & 17.41 (48 h) & 1741 & & 0.0115 \\
\hline \multirow{3}{*}{ SAs } & \multirow{3}{*}{ SMX } & Algae & $0.03(96 \mathrm{~h})$ & 3 & 12.48 & 4.16 \\
\hline & & Plant & $0.081(7 \mathrm{~d})$ & 8.1 & & 1.54 \\
\hline & & Invertebrate & $15.51(48 \mathrm{~h})$ & 1551 & & 0.008 \\
\hline \multirow{2}{*}{ MCs } & \multirow{2}{*}{ ROX } & Plant & $>1(7 \mathrm{~d})$ & 100 & 5.5 & 0.055 \\
\hline & & Invertebrate & $7.1(96 \mathrm{~h})$ & 710 & & 0.0078 \\
\hline
\end{tabular}

QNs in sediments [15]. These distribution patterns were likely due to the partitioning behaviors of antibiotics between sediments and water in the aquatic environment. For instance, SAs have the lowest $\mathrm{Kd}$ and Koc, which indicate their low sorption affinity to soil and sediment particu-

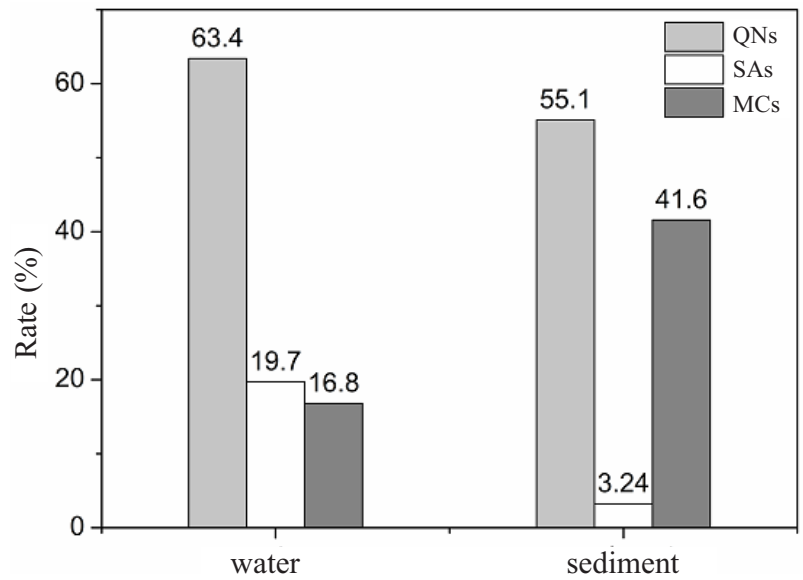

Fig. 2. Composition profiles of compounds in water and sediments.

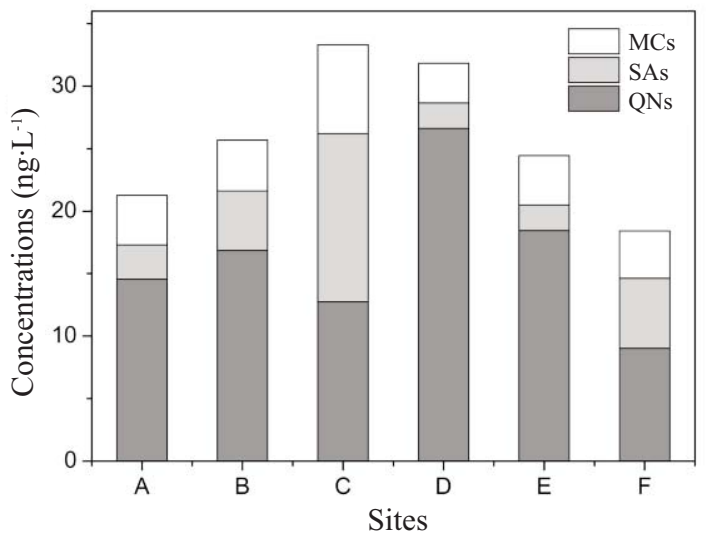

Fig. 3. Concentrations of antibiotics in water samples (ng/L). lates. Conversely, the high concentrations of QNs in sediments are related to their high potential to chelate with cations and bind with particulate matter, which delay their degradation [18].

\section{Risk Assessment}

Previous studies have reported that antibiotics in the aquatic environment may cause adverse impacts on humans. In this research, the ecological risk of the antibiotics in the water on organisms in Zizhuyuan Lake was estimated.

To assess potential risks from antibiotic exposure, the HQ values for individual contaminants were calculated as shown in Table 2. The extent of risk is dependent on the values of HQ, which can be classified into three categories. When the HQ value is between 0.01 and 0.1 , the risk is suggested to be low; when the HQ value is between 0.1 and 1 , the risk is regarded as medium; and if the HQ exceeds 1 , then the risk for the living organisms in this area is high. As shown in Table 2, the HQ values of OFL and SMX were 9.52 and 4.16 for algae, indicating that these two antibiotics were harmful to algae in the lake water. As for plants, OFL and SMX also have values higher than 1, indicating relatively high risk. Obviously, as for algae and plants, the pollution from antibiotics was significant in causing potential ecological problems in Zizhuyuan Lake. However, invertebrates in the lake are not likely at risk because their HQ values are far less than 0.1. Previous studies have reported that invertebrates are not likely to be affected [4].

Overall, such a risk assessment approach provides useful guidance about which chemicals to target for control based on those with high HQ values. However, this risk evaluation has its limitations, such as the lack of long-term toxicological studies, on the other hand, since a mixture of compounds with the same pharmacological mechanism is present in waters, synergistic effects could be expected, which can be more significant than individual effects. 


\section{Conclusions}

In this study, the levels of select antibiotics were investigated for water body and sediment samples collected from Zizhuyuan Lake. In water phase, QNs (especially the compounds NOR and OFL) had the highest concentration compared to other antibiotics. In the sedimentary phase, both contributions of QNs and MCs dominated. This shows that the antibiotic concentrations are related to human and aquaculture activities. Risk assessment of antibiotics on aquatic organisms suggests that algae and aquatic plants might be at risk in the lake water, while invertebrates were not likely at risk.

\section{Acknowledgements}

We gratefully acknowledge financial support through the China Central University Special Basic Research Fund (No. 2011QH01).

\section{References}

1. ANDREOZZI R., CAPRIO V., CINIGLIA C., DE CHAMPDORE M., LO GIUDICE R., MAROTTA R., ZUCCATO E. Antibiotics in the environment: occurrence in Italian STPs, fate, and preliminary assessment on algal toxicity of amoxicillin. Environ. Sci. Technol. 38, 6832, 2004.

2. SAPKOTA A., SAPKOTA A.R., KUCHARSKI M., BURKE J., MCKENZIE S., WALKER P., LAWRENCE R. Aquaculture practices and potential human health risks: current knowledge and future priorities. Environ. Int. 34, 1215, 2008.

3. XUE B.M., ZHANG R.J., WANG Y.H., LIU X., LI J., ZHANG G. Antibiotic contamination in a typical developing city in south China: occurrence and ecological risks in the Yongjiang River impacted by tributary discharge and anthropogenic activities. Ecotox. Environ. Safe. 92, 229, 2013.

4. KÜMMERER K. Antibiotics in the aquatic environment-a review-Part I. Chemosphere, 75, 417, 2009.

5. CONKLE J.L., LATTAO C., WHITE J.R., COOK R. Competitive sorption and desorption behavior for three fluoroquinolone antibiotics in a wastewater treatment wetland soil. Chemosphere, 80, 1353, 2010.

6. KARTHIKEYAN K.G., MEYER M.T. Occurrence of antibiotics in wastewater treatment facilities in Wisconsin, USA. Sci. Total Environ. 361, 196, 2006.
7. RADJENOVIC J., PETROVIC M., BARCELO D. Fate and distribution of pharmaceuticals in wastewater and sewage sludge of the conventional activated sludge (CAS) and advanced membrane bioreactor (MBR) treatment, Water Res. 43, 831, 2009.

8. GARCÍA-GALÁN M.J., DÍAZ-CRUZ M.S., BARCELÓ D. Occurrence of sulfonamide residues along the Ebro River basin: removal in waste water treatment plants and environmental impact assessment. Environ. Int. 37, 462, 2011.

9. YAN C.C., YANG Y., ZHOU J.L., LIU M., NIE M.H., SHI H., GU L.J. Antibiotics in the surface water of the Yangtze Estuary: occurrence, distribution and risk assessment. Environ. Pollut. 175, 22, 2013.

10. ZHOU L., YING G., ZHAO J., YANG J., WANG L., YANG B., LIU S. Trends in the occurrence of human and veterinary antibiotics in the sediments of the Yellow River, Hai River and Liao River in northern China, Environ. Pollut. 159, 1877, 2011.

11. LINDSEY M.E., MEYER T.M., THURMAN E.M. Analysis of trace levels of sulfonamide and tetracycline antimicrobials in groundwater and surface water using solidphase extraction and liquid chromatography/mass spectrometry, Anal. Chem. 73, 4640, 2001.

12. YANG J.F., YING G.G., ZHAO J.L., TAO R., SU H.C., LIU Y.S. Spatial and seasonal trends of selected antibiotics in Pearl Rivers, South China. J. Environ. Sci. Heal. B, 46, 272, 2011.

13. HERNANDO M., MEZCUA M., FERNANDEZALBA A., BARCELO D. Environmental risk assessment of pharmaceutical residues in wastewater effluents, surface waters nand sediments. Talanta, 69, 334, 2006.

14. LOPEZ-SERNA R.,POSTIGOC.,BLANCO J.,PEREZ S., GINEBREDA A., DE ALDA ML., PETROVIC M., MUNNE A., BARCELO D. Assessing the effects of tertiary treated wastewater reuse on the presence emerging contaminants in a Mediterranean river (Llobregat, NE Spain). Environ. Sci. Pollut. Res. 19, 1000, 2012.

15. LI W.H., SHI Y.L., GAO L.H., CAI Y.Q. Occurrence of antibiotics in water, sediments, aquatic plants, and animals from Baiyangdian Lake in North China. Chemosphere, 89, (11), 1307, 2012

16. GRACIA-LOR E., SANCHO J.V., HERNANDEZ F. Multiclass determination of around 50 pharmaceuticals, including 26 antibiotics, in environmental and wastewater samples by ultra-high performance liquid chromatography-tandem mass spectrometry. J. Chromatogr. A, 1218, 2264, 2011.

17. KIM S.C., CARLSON K. Temporal and spatial trends in the occurrence of human and veterinary antibiotics in aqueous and river sediment matrices. Environ. Sci. Technol. 41, 50, 2007.

18. TAMTAM F., MERCIER F., LE BOT B., EURIN J., TUC DINH Q., CLÉMENT M., CHEVREUIL M. Occurrence and fate of antibiotics in the Seine River in various hydrological conditions. Sci. Total Environ. 393, 84, 2008. 